\title{
DEL MITO DE LAS RAZAS A LA LEY DE GRESHAM
}

\author{
Hernán Gabriel Borisonik \\ Universidad de Buenos Aires \\ Instituto Gino Germani (CONICET)
}

Recibido: $26-11-2016$

Aprobado: 20-02-2017

Politólogo y doctor en Ciencias Sociales de la Universidad de Buenos Aires, donde dicta clases de teoría política en grado y posgrado. Investigador del Conicet, radicado en el Instituto Gino Germani, espacio en el forma parte de diversos proyectos de investigación vinculados a la teoría y la filosofía política. Sus temas de investigación centrales son la política, la economía y la sacralidad. Ha editado y coeditado diferentes volúmenes y ha publicado el libro Dinero sagrado. Política, economía y sacralidad en Aristóteles (2013).

hborisonik@gmail.com

\section{Resumen}

En la descripción de la comunidad ideal, que constituye la única forma de vida que Platón considera recta y buena, se observa la existencia de tres estamentos naturales, que responden a razas y están representados por metales (el hierro o el bronce, la plata y el oro). No deja de llamar la atención el hecho de que Platón haya elegido a estos materiales que, de hecho, funcionaban en la realidad de la polis como formas dinerarias. En efecto, algunas de las más antiguas alusiones al Ilamado "mito de las razas" se encuentran en Hesíodo, Píndaro y Heródoto, y en los tres casos el oro es vinculado con formas de nobleza o aristocracia.

En este texto, se analizan las relaciones y tensiones entre este mito y ciertos usos de la moneda en Grecia (echando mano también de Aristófanes y su crítica a la democracia ateniense), para pensar a la Ley de Gresham de la economía (que reza que el dinero de menor valor es utilizado y el de mayor valor, acumulado) como una expresión moderna de aquella fórmula mitológica.

Palabras clave: Mito; Política; Economía; Ley.

\section{Abstract}

In Plato's description of the ideal community, which is the only way of life that this thinker considered as right and good, one can compute the existence of three natural strata, responding to races and represented by different metals (iron or bronze, silver and gold). Is remarkable the fact that Plato has chosen those materials that actually worked in the reality of the polis as monetary forms. Indeed, some of the earliest references to the so-called "myth of the races" are in Hesiod, Pindar and Herodotus, and in all three cases gold is linked to forms of nobility or aristocracy.

In this text, the relationships and tensions between that myth and certain uses of money in Greece are analyzed (also making use of Aristophanes and his critique of Athenian democracy) to think Gresham's Law of the economy (which states that "bad money drives out good", e.g. the money of lowest social value is used and that of highest value is accumulated) as a modern expression of that mythological formula.

Key words: Myth; Politics; Economy; Law. 
Es de gran importancia, en este momento de la historia occidental, volver a reflexionar acerca del mito en torno de la palabra y las artes, así como también recuperar su dimensión política. El intento de este texto es llevar a cabo un acercamiento conceptual al "mito de las razas" o "mito de las edades" que circuló con fuerza en toda la Antigüedad y tratar de pensarlo en relación a la llamada "Ley de Gresham" de la economía moderna. ¿Por qué hacerlo? ¿Con qué fundamentos? Pues bien, porque es cardinal recordar y reflexionar profundamente sobre la fuerza del mito como manera de explicar la realidad, como forma de reafirmar determinados valores sociales. Además, porque particularmente la economía política moderna parece ser una gran heredera del esquema y los modos del mito antiguo, en tanto que "ciencia" (o "pseudo ciencia") cuyo espectro explicativo se reduce a un momento y una geografía muy concretos. Dicho de otro modo, porque la economía moderna se concibe como universal, pese a no serlo. Esto sería largo de demostrar en toda su extensión, y me escaparía del tema que de estas cortas palabras, pero baste por ahora con dejar expresado que, por ejemplo, Karl Polanyi, a mediados del siglo XX, explicó muy acabadamente la nonaturalidad o no-universalidad del mercado tal y como lo conocemos en la actualidad y fue claro al mostrar el precio que han debido pagar muchas sociedades para adaptarse -o someterse- a esa forma histórica (Polanyi, 1944; Bourdieu, 2013). Además, la coincidencia entre la jerarquía metálica que se encuentra en el mito y la que se ha usado casi invariablemente en la historia de las monedas, merece ser subrayada y analizada.

Como modo de ingresar en el problema principal, puede ser de utilidad repasar rápidamente el mito tal y como se lo encuentra en su primera expresión completa, es decir, en los versos de los Los trabajos y los días de Hesíodo (1998). Se puede decir que es su primera expresión completa, aunque hay diversos testimonios más antiguos de esta concepción en Grecia o incluso en otras culturas anteriores, aunque ninguno es tan claro y acabado como este. De hecho, en Homero ya aparecen mencionados unos "tiempos dorados" en los que había gran comunión entre los hombres y los dioses (Homero, 1991: libro I, 251-272; libro VII, 120-160).

Del mismo modo, en los textos de la Bhagavad-Gita (o en otros comparables, también pertenecientes a culturas orientales) se habla de una edad primera en la que los habitantes de la tierra eran fuertes, grandes, nobles y felices (y que vivían en una especie de paraíso), a 
diferencia de la edad "presente", llamada Kali-yuga, que es violenta y está llena de problemas (Carpenter, 1920: p. 137 y ss.; Nayon, 1984: p. 14).

¿Cómo presenta Hesíodo a este mito? A través de una historia que narra -luego de los relatos sobre Prometeo y Pandora- la existencia de cinco razas de hombres que fueron surgiendo sucesivamente: la Edad de oro (Hesíodo, 1998: versos 109-26); la Edad de Plata (12742); la Edad de Bronce (143-55); la Edad de los Héroes (156-73) y finalmente la Edad de Hierro (174-201) en la que viven los humanos tal y como los conocemos.

La primera raza, la de oro, es previa al gobierno divino de Zeus. Dice Hesíodo: "Al principio los Inmortales que habitan mansiones olímpicas crearon una dorada estirpe de hombres mortales. Existieron aquellos en tiempos de Cronos, cuando reinaba en el cielo; vivían como dioses, con el corazón libre de preocupaciones, sin fatiga ni miseria; y no se cernía sobre ellos la vejez despreciable, sino que, siempre con igual vitalidad en piernas y brazos, se recreaban con fiestas ajenos a todo tipo de males. Morían como sumidos en un sueño; poseían toda clase de alegrías, y el campo fértil producía espontáneamente abundantes y excelentes frutos. Ellos contentos y tranquilos alternaban sus faenas con numerosos deleites. Eran ricos en rebaños y entrañables a los dioses bienaventurados" (Hesíodo, 1998: versos 108-123).

Al morir, estos hombres áureos se convertían en divinidades benéficas que dispensaban riquezas desde debajo de la tierra. Esta referencia es muy relevante, dado que el oro, el dinero y la tierra formarían, también, parte del universo conceptual de Pluto, responsable de las fortunas materiales. Se observa ya aquí un claro vínculo entre el oro y las riquezas. Sin una explicación concreta acerca del porqué de la extinción de esta raza, Hesíodo pasa a describir a la siguiente, la plateada, mucho peor en su aspecto e inteligencia. En este caso, cada niño se criaba junto a su madre durante cien años, "pasando la flor de la vida, muy infantil, en su casa; y cuando ya se hacía hombre y alcanzaba la edad de la juventud, vivían poco tiempo llenos de sufrimientos a causa de su ignorancia; pues no podían apartar de entre ellos una violencia desorbitada ni querían dar culto a los Inmortales ni hacer sacrificios en los sagrados altares de los Bienaventurados, como es norma para los hombres por tradición. A éstos más tarde los hundió Zeus Crónida irritado porque no daban las honras debidas a los dioses bienaventurados que habitan el Olimpo" (Hesíodo, 1998: versos 130-139). Sin embargo, una vez enterrada 
esta generación de plata, también gozó de cierta consideración, aunque menor que el oro.

En tercer lugar, Zeus creó a los hombres de bronce, "nacida de los fresnos, terrible y vigorosa. Sólo les interesaban las luctuosas obras de Ares (dios vinculado con la guerra y la violencia) y los actos de soberbia; no comían pan y en cambio tenían un aguerrido corazón de metal" (Hesíodo, 1998: versos 145-148).

Tras ser aniquilada la raza de bronce por sus propias guerras fue creada una cuarta estirpe, más justa y noble, que es llamada "la de los héroes" o semidioses, que acabaría sus días combatiendo en torno a Tebas y Troya (los dos grandes ciclos épicos griegos) o viviendo para siempre en la Isla de los Afortunados. En comparación con los modelos anteriores del mito en el antiguo oriente, esta cuarta edad parece una inserción original de Hesíodo que se ha tratado de explicar de diversas maneras por los especialistas (por ejemplo, Fränkel, 1993: pp. 125-126).

Sea como sea, finalmente aparecen los hombres de hierro, última generación a la cual lamenta pertenecer Hesíodo, dado que los de esta raza "nunca durante el día se verán libres de fatigas y miserias ni dejarán de consumirse durante la noche, y los dioses les procurarán ásperas inquietudes; pero no obstante, también se mezclarán alegrías con sus males" (Hesíodo, 1998: versos 107-110). Entre ellos abunda la la discordia, la guerra, la enfermedad y la muerte y dependen del trabajo para obtener su sustento.

Ahora bien: las cuatro edades que preceden a la de hierro pueden dividirse en dos grupos, como bien lo explica Jean-Pierre Vernant, a través de la diferencia entre hybris y diké: mientras que los hombres de plata y de bronce se caracterizan por la desmesura, los de oro y los héroes viven con justicia (Vernant, 1985: pp. 19-45). A diferencia de todos ellos, los hombres de hierro debemos vivir bajo nuestras propias decisiones. En otras palabras, tanto la armonía como el exceso son formas que dominan a las razas sin mediar voluntades, mientras que a nosotros nos es presentado un mundo al que nos enfrentamos desde la contingencia, teniendo la pesada carga de tener que decidir entre lo justo y lo injusto.

A partir de la descripción de Hesíodo se observa, entonces, que quienes pertenecen a las mejores generaciones permanecen bajo la tierra y gozan de cierta dicha que la quinta estirpe no puede encontrar, entre sus fatigosos trabajos y su permanente estado de 
corrupción. En definitiva, quienes estamos sobre la tierra somos los menos aptos, mientras que los mejores se encuentran para siempre en otros sitios (bajo la tierra, en una isla).

La edad de oro pasó desde el siglo VII a.C. a ser una expresión común para designar a la abundancia y la felicidad, al tiempo que la concepción de distintas edades (no ya las cinco que enunciara Hesíodo, sino más bien agrupadas y resumidas en tres) se incorporaron al imaginario clásico impregnando profundamente la mentalidad del hombre antiguo. El oro como la plenitud, la plata como el vigor, y el bronce o hierro la corrupción.

Esta fórmula es también muy similar a la aplicada por Georges Dumézil (1971) a todo el mundo indoeuropeo y presenta como imposición a una división de funciones entre lo sagrado, lo político y lo productivo (la agricultura, la fecundidad), a la que se ven obligados los últimos hombres, por no ser autosuficientes ni poder existir por fuera de la contingencia. Las edades de oro y plata, sin embargo, no desaparecen completamente de la escena de la vida. Ya en Hesíodo hay indicios de cómo siguen operando a través de las riquezas que proveen.

Los ejemplos de esta repetición del mito de las razas en otros poetas griegos son múltiples, pero no es en eso en lo que quisiera detenerme ahora. Al contrario, sí me parece muy importante prestarle atención al modo en el que Platón se hizo eco de este mito. Ya en el Gorgias (Platón, 1987: parágrafo 523 b-e), hay algunos rudimentos de lo que luego será plasmado en la República (Platón, 1988) de manera más contundente, aunque presentado como una noble mentira que debe ser dicha para persuadir a los ciudadanos de que sólo los más virtuosos deben gobernar la polis. El relato platónico comienza postulando la hermandad entre todos los hombres y a su vez las diferencias entre ellos, a causa de portar en sus cuerpos oro (si están llamados a gobernar), plata (a quienes se desempeñarán como guardianes) o bronce y hierro (a los labradores y artesanos). Si bien en este libro Platón se dedica casi con exclusividad es las dos primeras clases, es muy claro que pretende, a partir del mito, crear un sentido opuesto al que observa a su alrededor, Platón esperaba que las mejores "monedas" fuesen las que se utilizaran y no que quedasen atesoradas, fuera de la vida de la polis, siendo reemplazadas en la acción por las de menor calidad. Esa me parece una forma categórica de definir a la democracia ateniense desde la perspectiva platónica: una polis en la que los mejores no están a la vista, y los peores ocupan la esfera pública. Esta 
perspectiva recoge claramente el problema de la contingencia, reflejada en la necesidad de un gobierno político para guiar las vidas de los hombres. Frente a eso, Platón espera que los ciudadanos más cercanos a los dioses, aquellos que están hechos de oro y son los más virtuosos, dejen la pura contemplación de lo perfecto, regresen a la caverna y convenzan al resto de la necesidad de ser gobernados por ellos. Esto es, que no queden por fuera de la vida pública, sino que se hagan visibles y se integren a la dinámica de la polis. Se ve con firmeza, una vez más, cómo la en la obra de Platón hay un uso claramente político de los mitos.

Esta visión tendrá también sus reverberaciones en la obra de Aristófanes, quien claramente comparte una mirada crítica sobre la democracia de la polis tardía y complementa (probablemente sin habérselo propuesto) las ideas de Platón. En Las ranas, este dramaturgo establece un sugerente paralelismo. Supone que las diferencias que existen entre los buenos y los malos ciudadanos son las mismas que entre las buenas y las malas monedas. Lo que Aristófanes plantea es que las monedas mal acuñadas terminaron por expulsar del uso y la circulación a las mejores. Simétricamente, el Coro expresa que los buenos ciudadanos habían sido dejados de lado, despreciados y ultrajados, mientras que los malos eran los que se habían vuelto más visibles. En esta extensa pero clarificadora cita se ve perfectamente lo recién expresado:

\footnotetext{
Muchas veces he tenido la impresión de que a esta ciudad le sucede lo mismo con sus ciudadanos nobles y buenos que con las monedas antiguas y el oro nuevo. $Y$ es que no usamos en absoluto aquéllas, que no están falsificadas, sino que, al parecer, son las más bellas de todas y las únicas bien acuñadas y de valor contante y sonante en todo el mundo, igual entre los griegos que entre los bárbaros, y sí estas otras, esa porquería ${ }^{1}$ de piezas de bronce, acuñadas ayer o anteayer y que son del peor cuño. E igual sucede con los ciudadanos, porque insultamos a todos cuantos sabemos que son bien nacidos, sensatos, justos, buenos y nobles, educados en las palestras, en los coros y en la música, y en cambio usamos para todo de esas piezas de bronce, esos extranjeros, esos con cabezas de espigas deformes, esa basura nacida de basura, esos recién llegados de los que en otro tiempo probablemente nuestra ciudad no se habría servido sin tomar precauciones, ni siquiera para usarlos como chivos expiatorios. Pero aún es tiempo, insensatos, de que cambien su manera de ser y usen a los buenos, porque se hablará bien de ustedes, si tienen éxito, y si fracasan habrá sido, por lo menos, empleando una madera digna de confianza (Aristófanes 2013: versos 720-730).
}

\footnotetext{
${ }^{1}$ Me he tomado la licencia de suavizar el término utilizado en el original.
} 
Lo que probablemente intentaba remarcar el autor con esta analogía era la decadencia de la calidad de los ciudadanos en la democracia radical que imperaba en Atenas durante el final del llamado período clásico. Sin embargo, al hacerlo dejó un testimonio de la tendencia a la forma que tomaba la acumulación de metálico, que también caracterizó a los ciudadanos de ese momento histórico.

Con todo lo recién dicho queda delineada la forma general y algunos de los avatares que el mito de las razas tuvo en Grecia. Pero el tema ha trascendido ese escenario hasta nuestros días, a través de algunas importantes mediaciones. La expresión romana del mismo relato se encuentra en Ovidio, quien sólo describe cuatro edades en el libro I de su célebre poema Las metamorfosis. Su mito es muy similar al de Hesíodo, aunque omite la Edad de los Héroes. Además, en la Edad de Hierro, postula la demarcación de las fronteras entre las naciones, acompañada de guerras, codicia y falta de verdad.

Más tarde, la llegada del cristianismo imprimió también su marca en el mito. Jerónimo de Estridón llevó adelante una datación de las edades, asociándolas al tiempo lineal del monoteísmo y pretendiendo ubicarlas en un pasado concreto, separándolas de la opacidad de los mitos antiguos. Para él, la Edad de oro ocurrió entre 1710 y 1674 a. C., la Edad de Plata, entre 1674 y 1628 a. C., la de bronce entre 1628 y 1472 a. C., la Edad de los Héroes entre los años 1460 y 1103 a. C. Y finalmente la Edad de Hierro desde el año 1103 a. C. al menos hasta el siglo IV d. C., en el que vivió este religioso (Jerónimo, C. 382). Por su parte, Dante Alighieri en La divina comedia hace alusión a este mito en el canto XXVIII del Purgatorio, donde se encuentra una expresa referencia a la Edad de oro como momento glorioso en el que la tierra daba permanentemente frutos y reinaba la felicidad.

Como se sabe, los mitos en la Antigüedad no eran otra cosa que un método para explicar la realidad, a partir de relatos sobre los orígenes de determinadas relaciones. Éstos estaban fuertemente atados a los vaivenes políticos y es por eso que se pueden encontrar siempre varias versiones de cada uno de los temas que atravesaban la vida de los hombres. La convivencia entre el mito y el discurso filosófico (el logos) fue por algún tiempo pacífica, hasta que, alrededor del siglo $\mathrm{V}$ a. C., comenzaron a oírse opiniones peyorativas a este tipo de explicaciones, en beneficio de la lógica más especulativa de la filosofía. Sin embargo, la forma mítica siguió 
funcionando, tanto entre los ciudadanos menos ilustrados de Grecia, como luego en toda la historia, bajo las más diversas mediaciones y arbitrariedades ${ }^{2}$.

Al comenzar el proceso que conocemos como Modernidad, uno de los aspectos que se impuso fue el de la idea de leyes naturales que los hombres podían descubrir a través de la razón y la ciencia. Esta creencia fue de enorme importancia para el desarrollo técnico y tecnológico que la humanidad conoció desde el siglo XVI, lo cual no quita que haya, incluso en el discurso científico más "duro", una serie de axiomas que son aceptados casi dogmáticamente y que recubren, de forma sofisticada, mitos modernos que aún funcionan como explicaciones del mundo en el que vivimos. La Ley de Gresham es uno de esos casos.

Como se ha visto, esta "ley" ya operaba mucho antes de su formulación formal. Sin embargo, fue hacia el fin de la Edad Media que esta idea circuló con fuera, dado que en ese momento convivían muchas formas monetarias diferentes. Tal es así, que los mercaderes itinerantes hacían descuentos a quienes pagaran con monedas más pesadas o de mejor calidad.

La expresión "Ley de Gresham" fue realmente creada por el economista escocés Henry McLeod en 1858. Este economista hablaba de monedas "superiores" e "inferiores", lo cual muestra que esta ley está vinculada a una concepción metalista del dinero. En su interpretación moderna, la Ley de Gresham fue comprendida como una aplicación al dinero de las leyes de la oferta y la demanda, es decir, de las reglas del mercado como asignador eficiente y natural de todos los bienes.

Si bien Thomas Gresham era un financista británico que no produjo ningún desarrollo teórico (y cuyas formulaciones han llegado a nosotros más bien gracias a la tradición) ya el momento histórico en el que advirtió empíricamente que las personas preferían siempre pagar con las monedas más defectuosas o con menor valor metálico estaba teñido de ciertas ínfulas cientificistas que la Antigüedad había desconocido. Si pensamos por un instante en René Descartes o en Thomas Hobbes, veremos que el tipo de planteo más racionalista se estaba imponiendo durante la Modernidad temprana. Pero incluso yendo más atrás, en los debates tardomedievales podremos encontrar en Guillermo de Ockham (en el siglo XIV) la utilización de la

\footnotetext{
${ }^{2}$ Un autor de enorme utilidad para rastrear esta presencia mítica en el Medioevo y el Renacimiento es Aby Warburg.
} 
"ley natural" como categoría explicativa del comportamiento humano (Ockham, 1974).

El aporte de Gresham a la economía de su época fue significativo. Gracias a su planteo, los primeros bancos y varios empresarios modificaron algunas de sus prácticas con el fin de obtener más ganancias, así como ciertos gobiernos llevaron adelante devaluaciones que no involucraran la introducción de nuevos metales. Schumpeter, en su célebre libro Historia del análisis económico, plantea que la Ley de Gresham (explicada rápidamente como que "la moneda mala expulsa a la buena") fue probablemente definida por su moderno autor en 1559 (Schumpeter, 1986: p. 324, nota 4), año en el que fue llamado por la Reina Isabel (Elizabeth) como consejero para las finanzas y las reformas monetarias. De todos modos, muchos libros de economía contemporáneos reconocen en Aristófanes un antecedente insoslayable para esta construcción.

El entusiasmo con el que, paulatinamente, pero por lo menos desde el siglo XVI, políticos y pensadores tomaron esta ola de naturalismo no podría explicarse fuera del contexto específico de la Modernidad. Si el siglo XIX puede ser tomado como un momento de auge del liberalismo, el siglo XVII constituye el golpe final a las tradicionales relaciones feudales de dominación extraeconómica. Y fue durante aquella transición que una nueva lectura acerca de qué es y cómo se expresa la naturaleza hizo su entrada triunfal.

Durante la Modernidad, pasó a ser un lugar común (por su aceptación casi absoluta) postular que las relaciones sociales, interpersonales, políticas y económicas estaban determinadas por designios de la naturaleza. Hay innúmeros ejemplos, tales como las "leyes del mercado", la "ley de la oferta y la demanda"3, la "ley de hierro de los salarios" de David Ricardo (1821: cap. V), la "ley de la población" de Thomas Malthus (1798), la "ley de los rendimientos decrecientes" de Johann Heinrich von Thünen ${ }^{4}$-entre otros- e incluso Marx con su "ley general de la acumulación capitalista" (Marx, 2008: libro I, cap. XXIII) o Freud con sus "leyes del inconsciente" Freud, 1900). Todas estas formalizaciones dan cuenta de la certeza que el capitalismo avanzado tenía de la existencia de regularidades cuasi mecánicas con mayor poder que cualquier regla jurídica o moral sobre las decisiones personales o políticas. Como lo postula Carl Polanyi, en esta época, "finalmente, la sociedad humana se había

\footnotetext{
${ }^{3}$ Cfr., como posible origen del concepto, James Steuart (1885).

${ }^{4}$ Allí hay una primera teorización sobre el aumento de las pérdidas en relación al aumento de la extensión de las propiedades rurales, que luego se repetirá en varios autores.
} 
convertido en un accesorio del sistema económico" (Polanyi, 1944: p. 79), dentro del cual "las leyes del comercio eran las leyes de la naturaleza y consecuentemente las leyes de Dios" (Polanyi, 1944: p. 122). Ahora bien, dado que la creencia en el gobierno de leyes naturales sobre las actividades humanas es tan arbitraria como la afirmación de que son guiadas por una voluntad divina (o demoníaca), es importante para nosotros interpretar a estas ideas como decisiones políticas, como acciones determinadas histórica e ideológicamente.

Para finalizar estas breves palabras, sólo hace falta dejar brevemente planteadas un par de cuestiones para seguirlas pensando (ojalá juntos) y ver si nos conducen hacia algún lado.

En primer lugar, destacar la importancia del mito como forma de explicación de la realidad que admitía ser modificada por la voluntad (voluntad política, agregaría yo) de los poetas y las sociedades que los contenían. Pero por otro lado, observar que la forma más lábil que portaba la mitología, fue revestida en la Modernidad por un viso de "Verdad" que ha tendido a calcificar y reificar ciertas concepciones que sólo funcionan en contextos muy específicos.

Frente a ello, la pregunta por los mitos modernos debe necesariamente reabrirse, sobre todo hoy, que las posibilidades de vida de tantas personas se encuentran en condiciones tan o más precarias que en momentos pre científicos de la humanidad.

\section{BIBLIOGRAFÍA}

Alighieri, Dante. La divina comedia. Traducción en verso ajustada al original por Bartolomé Mitre; edición definitiva de Nicolás Besio Moreno. Buenos Aires: Centro Cultural Latium, 1922. En Biblioteca de Traductores. Dirección: http://www.traduccionliteraria.org/biblib/D/D102.htm. Consulta 11 de julio de 2016.

Aristófanes (2013) Comedias III. Lisístrata, Tesmoforiantes, Ranas, Asambleístas, Pluto. Madrid: Gredos.

Bourdieu, Pierre (2013) Argelia 60. Buenos Aires: Siglo XXI editores.

Carpenter, E. (1920) Pagan and Christian Creeds: Their Origin and Meaning. Nueva York: Harcourt, Brace and Company (versión online). Dirección: http://sacred-texts.com/cla/pcc/index.htm. Consulta 11 de julio de 2016.

Dumézil, Georges (1971) Los dioses de los indoeuropeos. Barcelona: Seix 
Barral.

Fränkel, H. (1993) Poesía y filosofía en la Grecia arcaica. Madrid: Visor.

Freud, Sigmund (1900). "Die Traumdeutung". En: Studienausgabe. Vol. II. Frankfurt am Main: Verlag.

Hesíodo. (1998) Teogonía - Los trabajos y los días. Madrid: Gredos.

Homero. (1991) La llíada. Madrid: Gredos.

Jerónimo de Estridón (Circa 382) Crónica. En: Early Church Fathers. Dirección:

http://www.tertullian.org/fathers/jerome_chronicle_01_prefaces.htm.

Consulta 11 de julio de 2016.

Malthus, Thomas (1798) An Essay on the Principle of Population. Londres: Johnson.

Marx, Karl (2008) El capital. Crítica de la economía política. Trad. Pedro Scaron. México: Siglo XXI editores.

Neyton, A. (1984) L'âge d'or et l'âge de fer. París: Les belles lettres.

Ockham, Guillermo de (1974) [1940]. Opus nonaginta dierum. En Sikes, J.G.; Offler, H.S. (eds.) Guillelmi de Ockham Opera politica. 4 vols. $2^{a}$ edición. Manchester: Manchester University Press. Vol. I, pp. 292-368.

Platón (1987) Gorgias, Menéxeno, Eutidemo, Menón, Crátilo. Madrid: Gredos.

Platón (1988) República. Madrid: Gredos.

Polanyi, Karl. (1944) The Great Transformation: The Political and Economic Origins of Our Time. Boston: Beacon Press.

Ricardo, David (1821) On the Principles of Political Economy and Taxation. Tercera edición. Londres: John Murray.

J.A. Schumpeter, J. A. (1986) History of Economic Analysis. Londres: Routledge.

Steuart, James (1885) An Inquiry into the Principles of Political Economy. Being an Essay on the Science of Domestic Policy in Free Nations, in which are particularly considered Population, Agriculture, Trade, Industry, Money, Coin, Interest, Circulation, Banks, Exchange, Public Credit, and Taxes. Nueva York: Appleton And Company. 
Vernant, J-P. (1985) "Le mythe hésiodique des races. Sur un essai de mise au point". En: Mythe et pensée chez les Grecs. París: Éditions de la Découverte.

von Thünen, Johann (1910) Der isolirte Staat in Beziehung auf Landwirthschaft und Nationalökonomie. Jena: Fischer. 